Review

\title{
Fiber-Optic Sensor Applications in Civil and Geotechnical Engineering
}

\author{
Wolfgang R. HABEL and Katerina KREBBER \\ Federal Institute for Materials Research and Testing; Division VIII.1: Measurement and Testing Technology; Sensors, \\ D-12205 Berlin, Germany \\ *Corresponding author: Wolfgang R. HABEL_Ｅ-mail: wolfgang.habel@bam.de
}

\begin{abstract}
Different types of fiber-optic sensors based on glass or polymeric fibers are used to evaluate material behavior or to monitor the integrity and long-term stability of load-bearing structure components. Fiber-optic sensors have been established as a new and innovative measurement technology in very different fields, such as material science, civil engineering, light-weight structures, geotechnical areas as well as chemical and high-voltage substations. Very often, mechanical quantities such as deformation, strain or vibration are requested. However, measurement of chemical quantities in materials and structure components, such as $\mathrm{pH}$ value in steel reinforced concrete members also provides information about the integrity of concrete structures. A special fiber-optic chemical sensor for monitoring the alkaline state ( $\mathrm{pH}$ value) of the cementitious matrix in steel-reinforced concrete structures with the purpose of early detection of corrosion-initiating factors is described. The paper presents the use of several fiber-optic sensor technologies in engineering. One example concerns the use of highly resolving concrete-embeddable fiber Fabry-Perot acoustic emission (AE) sensors for the assessment of the bearing behaviour of large concrete piles in existing foundations or during and after its installation. Another example concerns fiber Bragg grating (FBG) sensors attached to anchor steels (micro piles) to measure the strain distribution in loaded soil anchors. Polymer optical fibers (POF) can be - because of their high elasticity and high ultimate strain - well integrated into textiles to monitor their deformation behaviour. Such "intelligent" textiles are capable of monitoring displacement of soil or slopes, critical mechanical deformation in geotechnical structures (dikes, dams, and embankments) as well as in masonry structures during and after earthquakes.
\end{abstract}

Keywords: Fiber-optic sensor, monitoring, earthquake damage assessment, steel-reinforced structures, pH sensor, geotextiles, distributed sensor

\section{Introduction}

Fiber-optic sensor (FOS) technology has gained worldwide recognition due to its specific characteristics. In engineering, it is mainly used to monitor deformation and/or the overall integrity of structure components with high level of risks or with high safety requirements. Especially in steel-reinforced concrete structures, such fiber-optic sensors that have the potential to provide early online information about danger of corrosion are demanded. Fiber-optic sensor-based monitoring methods are highly welcome for non-destructive assessment of all types of geotechnical and engineering structures because these methods:

1)cannot be destroyed by lightning strokes,

2)survive in chemically aggressive environments,

3)can be integrated into very tight areas of

Received: 21 September 2010 / Revised version: 18 November 2010

(C) The Author(s) 2011.This article is published with open access at Springerlink.com 
structural components, like anchor rods, ropes, composite components, layered concrete elements, and

4)enable to deliver sensor chains using one single fiber.

The use of fiber-optic sensor systems can be divided, in general, into two main steps:

a)Installed or integrated sensors are activated during testing the structure integrity to collect data about the performance of structure components. Such measurements are mostly carried out periodically, and the sensor state can then be considered as "zero-point" state.

b)In contrast to this procedure, sensors that have to deliver data from the measuring object with reference to the previous measurement must work reliably and stably over years. They must not loose the reference value from the beginning of the signal recording. There are high demands both for operational safety of the sensor system and for reliability of all components (long-term stability of sensor characteristics and related components, accuracy, repeatability of recorded data, consideration of temperature influence, ...). If zero-point drifts occur, they must be separated from the measurement information. This task might be challenging because the recalibration of sensing elements is, in general, not possible after installation respectively after the first test loading.

In the following sections, the use of different fiber sensor types based on glass and polymeric optical fibers (POF) in selected fields of civil and geo-engineering is described.

\section{Short-gauge length sensor applications}

\subsection{Assessment of large concrete foundation piles by fiber-optic acoustic emission sensors}

\subsubsection{Assessment problem}

In order to get information about the integrity and ultimate bearing capacity of large concrete piles in existing or newly constructed foundations, sensors are usually attached to the reachable part of the concrete component such as the pile head. Propagating waves are then excited by an impact at the pile head. The sensors record the acoustic emission (AE) signals from the concrete structures. The bearing capacity and the pile performance can then be estimated using one dimensional theory of wave propagation. Especially for cohesive soil areas, one can only make vague assumptions about pile-soil interaction as well as material and subsoil conditions. Often, the commonly used instrumentation at pile head does not provide sufficient information.

\subsubsection{Sensor development and model pile tests}

In order to improve the performance analysis of large concrete piles, highly resolving fiber-optic acoustic emission sensors based on extrinsic Fabry-Perot interferometer (EFPI) sensor technology have been developed for embedment in concrete piles at several levels. Fiber Fabry-Perot sensor elements enable recording dynamic signals up to the range of several hundreds kilohertz. This method promises to provide more precise information about the pile response over the whole pile length especially using dynamic pile test methods.
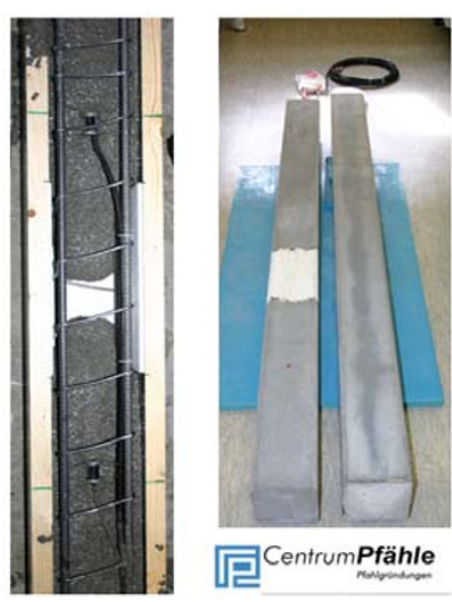

Fig. 1 Casting of sensor-equipped model piles (sensors are fixed at the cage of reinforcement (left); one pile has got an imperfection (left pile in the right picture)).

Prefabricated model piles (Fig. 1) are equipped with sensors and tested in laboratory to prove the appropriateness of the developed concrete 
embeddable sensors which will be subjected to high impact energy during test.

A special sensor body is developed to which different sensing elements are attached. The fiber-optic acoustic emission sensors are attached to the inner surface of the sensor body by using a special tool. For comparison purposes, accelerometer sensors are installed inside of the sensor body; resistance strain gauges (RSG) are attached to the outer surface of the body.

These two small scale model piles have been investigated by dynamic low-strain tests, high-strain and static load tests [1]. All signal responses from integrated sensors have been recorded and compared with signals obtained from common methods of instrumentation.

\subsubsection{Test results from low-strain integrity method}

Figure 2 compares strain responses of EFPI sensors from one pile without imperfection (above) and the other one with imperfection (below) during low-strain integrity test. From the undamaged pile response (Fig. 2, above), it can be seen that the introduced wave travels from pile head passing to the embedded sensors at measuring levels ML1, ML2, and ML3 to the pile toe and back to the pile head. The simulated geometric defect of 30-cm length in the direction of pile axis at pile 2 is marked with dotted circles as seen in the lower picture of Fig. 2.

The length of the defect, which could be calculated from the measured travel time difference from pile head (sensor is installed at the pile head) to the secondary peaks at pile 2 , is $31.7 \mathrm{~cm}$. By applying the same procedure, however using embedded sensors, a defect length of $29.6 \mathrm{~cm}$ follows from ML1 and $30.3 \mathrm{~cm}$ follows from ML3. These measured results from embedded sensors are definitely better consistent with the real defect length of $30 \mathrm{~cm}$. It must be noted that ML2 does not show significant secondary peaks caused by superposition of reflecting wave parts from very closely located defect and the applied impact wavelength. The tests carried out confirm the application concept for Fabry-Perot sensors to the inner surface of the sensor body.
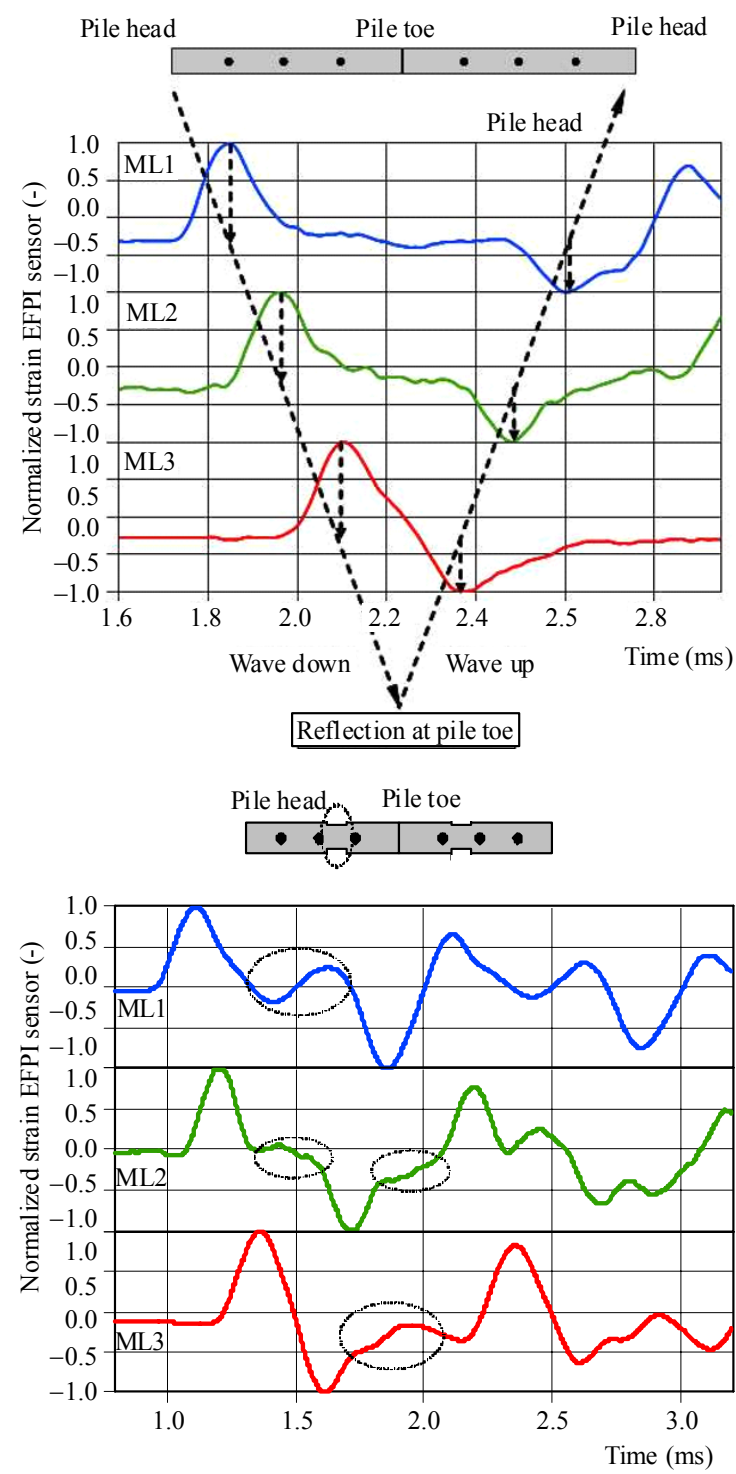

Fig. 2 Strain responses of EFPI sensors over time from one pile without imperfection (above) and the other one with imperfection (below) during low-strain integrity testing; impact was generated by steel ball with a diameter of $40 \mathrm{~mm}$ (falling height: $60 \mathrm{~cm}$ )

\subsubsection{Conclusions from load test in laboratory}

Strain results from all applied strain gauges (RSG and EFPI) for high-strain pile test are shown in Fig. 3. 


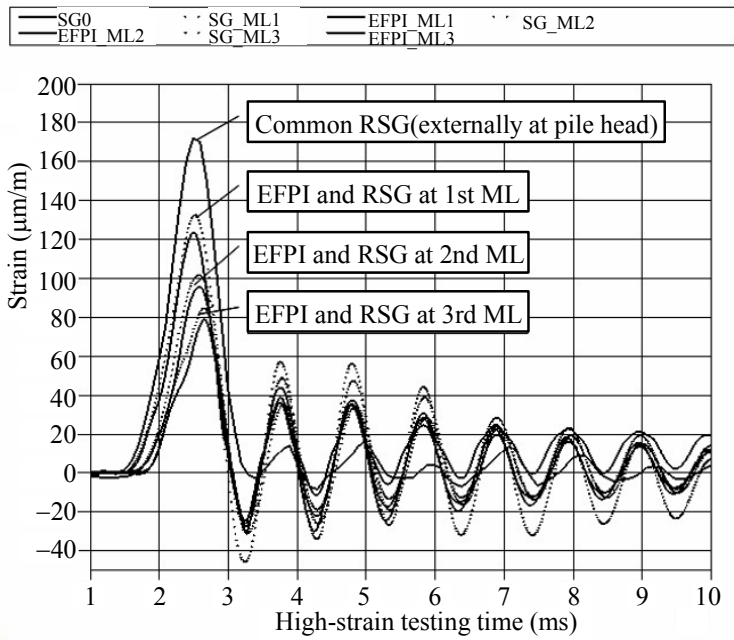

Fig. 3 Strains measured during high-strain test.

The reduction in EFPI strain intensity from one measuring level to the next one caused by friction forces can clearly be seen. This reduction in strain is also caused by radiation damping losses at pile skin and toe. On the other hand, comparison of internal strain from embedded Fabry-Perot sensors (EFPI_ML1, 2, 3) with resistance strain gauges (SG_ML1, 2, 3) at the same location at each measuring level reveals that both measuring systems vary in a range of about $5 \%$.

Although the concrete embeddable strain sensor is developed for acoustic emission signal recording, static load tests are carried out as well at both model piles. Loads are applied in three cycles. The maximum load is $110 \mathrm{kN}$ which leads to a permanent pile head settlement of $50 \mathrm{~mm}$ in dimension after the third loading cycle. Comparison of both sensor systems reveals good agreement; the measurement results achieved from EFPI sensors and resistance strain sensors differ in the range of $5 \%$ to $10 \%$. Comparing the shapes of strain curves, it can be concluded that the pile concrete transfers strain properly to the sensor body. Detailed description of the laboratory tests is given in [1].

The main outcome of the measurement results is that EFPI sensors embedded as described above can be used for both dynamic pile test under low-strain as well as high-strain loading conditions and static load test. It is possible to calculate the bearing capacity of piles in the same way as made with standard methods which use additionally embedded accelerometers. In addition, calculations can be made on the basis of measurements at different locations which provide more precise information about the pile's bearing behaviour. Therefore, the usually required number of assumptions for calculation of bearing capacity can strongly be reduced.

\subsubsection{Field tests with adapted sensor bodies}

Field tests have been carried out to show the ability of this sensor body to survive very heavy dynamic impact energy onto real precasted driven piles.

The design of the sensor body was matched to the concrete mixture (aggregate size) and dynamic loading conditions of the real concrete pile dimensions. Eight sensors were located in 5 measuring levels along a 19-m-length concrete pile. The locations were defined depending on the soil stratification. Figure 4 shows the cage of reinforcement with the fixed sensors before concreting. Figure 5 (left) shows a sensor-equipped 19-m-length pile during erection; the right picture shows the piles already driven into soil. It can be stated that all sensors survived the high impact energy during the driving process. Since two EFPI sensors and three RSG were attached to each sensor body, a total number of 40 strain gauges had to be controlled.

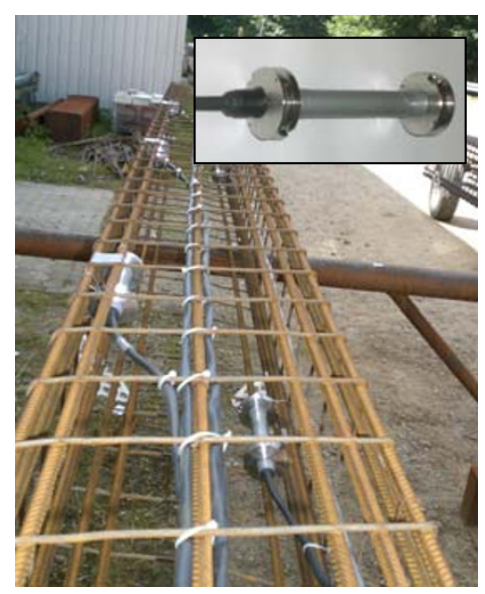

Fig. 4 Sensors fixed at the cage of reinforcement for a 19-m-length concrete pile (above right: sensor body). 


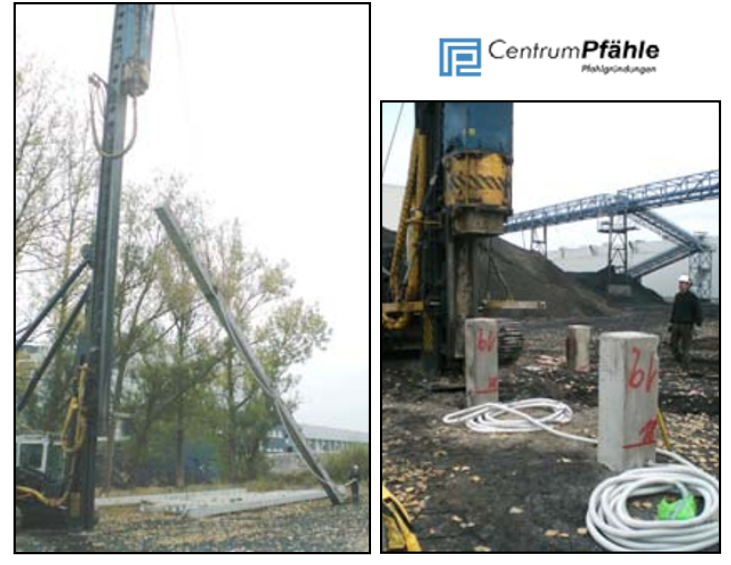

Fig. 5 Precasted sensor-equipped piles before and after driving process.

A special measuring device developed at the Federal Institute for Materials Research and Testing (BAM) Germany and a conventional multi-channel data acquisition system have been used. A sampling rate of $100 \mathrm{kHz}$ per channel could be realized for dynamic loading conditions.

One day after pile driving, dynamic load testing (DLT) was applied to both piles. All EFPI sensors survived this load application, too. Whenever a change in strain appeared, a change in the EFPI signal output occurred. Figure 6 shows the good agreement between RSG and EFPI from DLT.

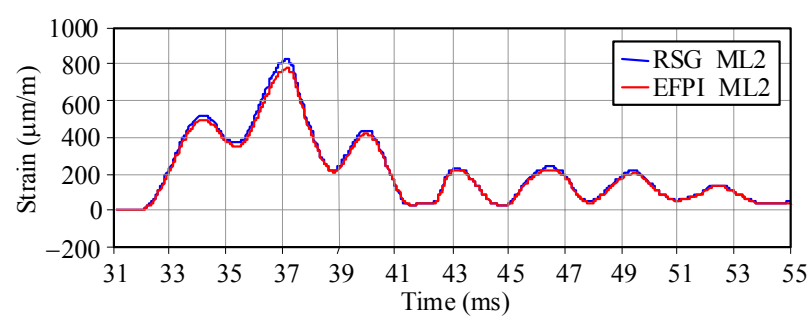

Fig. 6 Comparison of strain from embedded RSG and EFPI at ML2 for dynamic load testing.

Figure 7 shows the result of the same ML 2 from the static load testing (SLT). The comparison of both embedded measuring systems shows again a very good agreement. Generally, EFPI sensors show lower values in strain than RSG at the same location.

It can be concluded that fiber-optic extrinsic Fabry-Perot interferometer sensors can be used for low-strain and high-strain dynamic pile tests as well as static load tests. Field tests show that the developed concrete-embeddable fiber-optic sensor provides data for all of three different test methods with only one measurement system. Especially during pile integrity tests (PIT), Fabry-Perot sensors record very small deformation inside the concrete structure, and by using a number of embedded sensors distributed along the pile length at defined locations, PIT allows the determination of material properties by calculating the wave velocity of different pile sections separately. The field tests show also good agreement with the results from both measurement systems. Details of field tests are described in [2, 3]. The sensor system is being transferred into a product for commercial use.

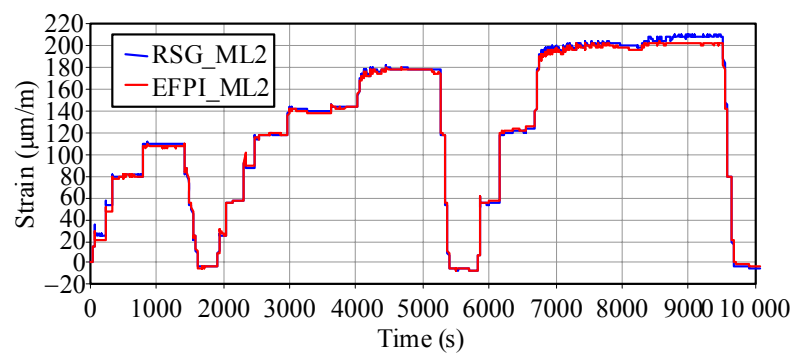

Fig. 7 Comparison of strain from embedded RSG and EFPI at ML2 for static load testing.

\subsection{Evaluation of bearing behaviour of large steel anchors and micro piles}

\subsubsection{Evaluation problem}

The classical way to evaluate the bonding of the fixed anchor length in difficult soil areas and/or to carry out suitability tests is to pull the fixed anchor out and measure the resulting forces at the anchor head. This test method delivers integral information whether the introduced anchor forces will be transferred into the soil area, or not. However, it does not provide any information how is the skin friction distribution along the steel anchor and finally to which amount is the length of the anchor involved in the load bearing. In order to get information on the force distribution of the anchors, fiber Bragg grating sensor arrays were attached to the surface of steel bars (micro piles with a diameter 
of $80 \mathrm{~mm}$ ) to evaluate the load transfer behaviour. This method was used, first, to probe micro piles (type GEWI ${ }^{\circledR} 63.5 \mathrm{~mm} \mathrm{Z-32.1-9/1/)} \mathrm{that} \mathrm{were} \mathrm{to} \mathrm{be}$ used for fixing of foundation plates of a sluice in the German river Weser against uplift.

Already in the early 90's of 20th century, optical fibers were integrated into extremely heavy steel strand anchors $(4,500 \mathrm{kN}$ tensile force each) installed to stabilize a large gravity dam in Germany. These sensors provided a long-term monitoring of the integrity of the fixed anchor length. The measurement method based on optical time domain reflectometry (OTDR) principle is described in [4].

\subsubsection{Measurement concept and sensor installation}

In order to find the most economic method to obtain the necessary information, a measuring concept was developed and implemented in interdisciplinary cooperation between the Federal Institute for Materials Research and Testing (BAM) Berlin, Neubauamt für den Ausbau des Mittellandkanals in Hannover, German Federal Waterways Engineering and Research Institute (BAW) and the Consulting Office Dietz Geotechnik Consult Hilden/Germany. The quasi-distributed fiber-optic strain sensor arrays were installed in the complete length of GEWI ${ }^{\circledR}$ steel bar (maximum length: $18 \mathrm{~m}$ ) to measure strain distribution in the loaded anchors/micro piles. The gauge length for each sensor in the chain was $200 \mathrm{~mm}$; the distance between the sensors was between $750 \mathrm{~mm}$ and $1500 \mathrm{~mm}$. Each bar was equipped with two sensor arrays for redundancy reasons.

Figure 8 shows fiber Bragg grating (FBG) installation in the anchor factory, and Fig. 9 (left) shows the splice box where sensor fiber and leading cable are connected. Importance is reliable fixing and protection of the sensors as well as safe cable egress at the anchor head (Fig. 9, right) because the sensor-equipped anchors have to be transported to the building site over several hundreds kilometers.

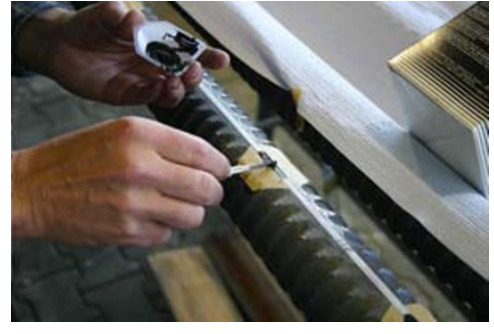

Fig. 8 Application of FBG sensor to the steel bar.
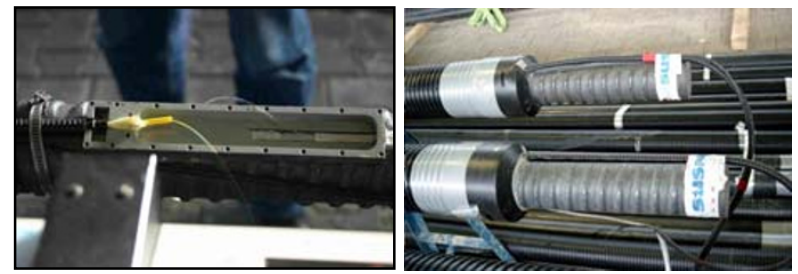

Fig. 9 Splice box (left) and cable protection at the pile head (right).

\subsubsection{Tests and results}

After the anchors were installed (Fig. 10) and the grout was cured, pull-out tests were carried out in December 2006. The tensile force during anchor tests was stepwise increased up to $1,580 \mathrm{kN}$, and the strain distribution along the fixed anchor length was measured. From the measured strain in the fiber Bragg grating sensors, the strain distribution along anchor was calculated. Figure 11 shows the result for one anchor. Above solid line, the strain distribution along the steel rod which is not fixed in soil (free anchor length) is plotted; below the line, the strain distribution along the fixed anchor length represents the load transfer into the soil (load bearing).

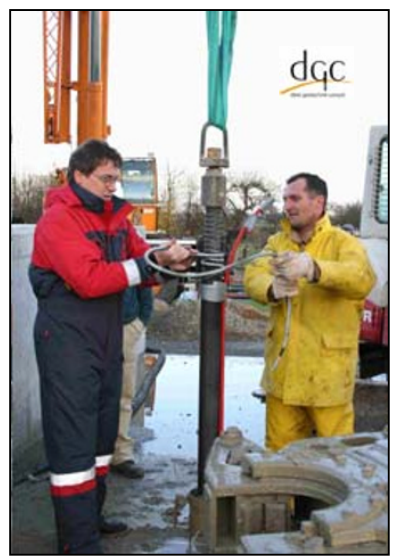

Fig. 10 Introduction of the micro pile into the bore hole. 


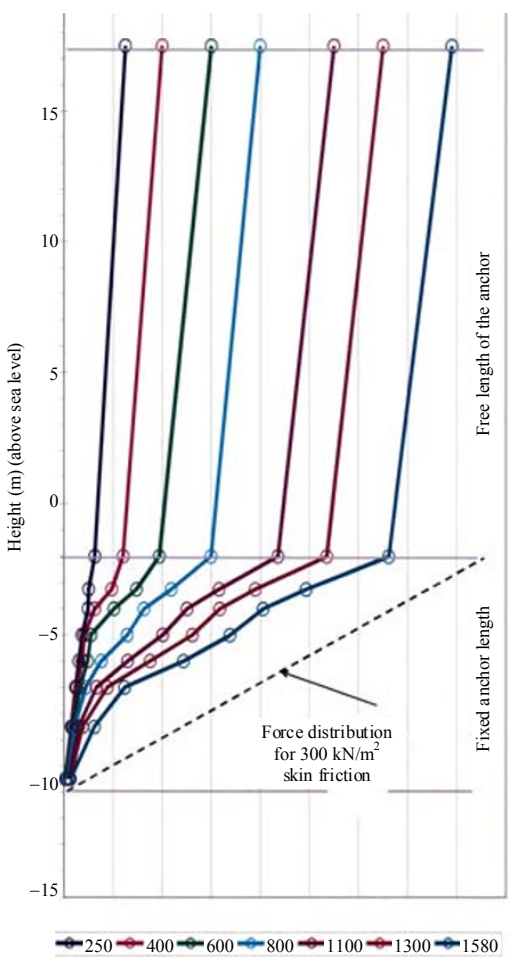

Fig. 11 Load transfer of anchor A1 measured with applied strain sensors (diagram source: German Federal Waterways Engineering and Research Institute, BAW).

\section{Long-gauge length sensor applications}

\subsection{Distributed silica-based fiber sensors for monitoring of geo-structures with large dimensions}

Monitoring of extended structures such as dikes, dams, tracks, and highways in mining or critical soil areas requires sensor technologies with gauge lengths in the range of several hundreds meters or even several kilometers. Sensing systems using stimulated Brillouin scattering (SBS) allow the design of fully distributed fiber-optic sensors that monitor strain and temperature along optical fibers over a length of more than $10 \mathrm{~km}$. This makes them highly suitable for the application in geo-engineering or in extended structures like bridges.

Because of extreme floods in two large German rivers (Oder in 1997 and Elbe in 2002), the national "Risk Management of Extreme Flood Events (RIMAX)" research programme was started by the German Federal Ministry of Education and Research to develop intelligent monitoring systems which were able to detect incipient effects of failure of hydraulic engineering structures. The idea was to integrate fiber-optic sensors into geosynthetics, which were to be used for the stabilization of dikes, dams or similar geotechnical structures. Geosynthetics are commonly used in dikes, where they act as filter, drainage or reinforcement. Equipped with fiber-optic sensors, they form a smart sensing structure which can be embedded into the soil along the landside dike foot, as outlined in Fig. 12.

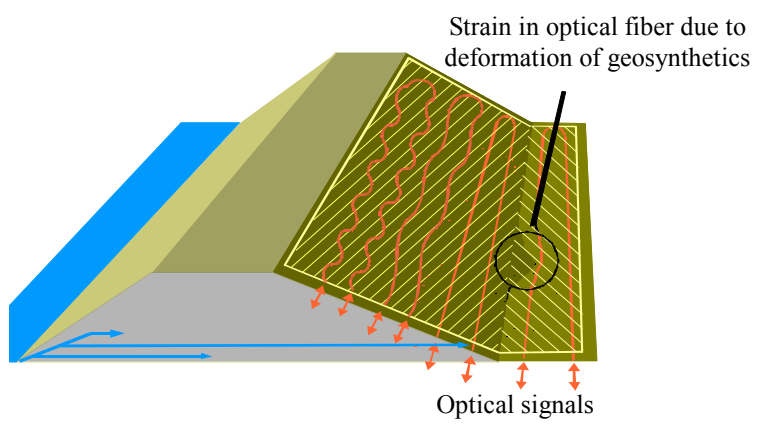

Fig. 12 River dike with sensor-based geosynthetics.

In case of a critical deformation of dike body caused by erosion, slope failure, wave overtopping or piping, the soil displacement is transferred to strain experienced by optical fiber. The strain can be detected by a distributed fiber-optic strain sensor.

Currently, a distributed cost-effective field-applicable sensing system is being developed which is based on the Brillouin frequency-domain analysis (BOFDA) technique and fulfil the requirements on dike monitoring, having a spatial resolution of $5 \mathrm{~m}$ or better.

The feasibility of this novel combination of coated optical fibers and geosynthetics has been proven in several field tests. Figure 13 shows such a geotextile with integrated sensor fibers during the installation in a gravity dam in Solina/Poland. Measurement system, test results, and application as well as the theoretical background of this measurement method adapted to the requirements of geotechnique are described in detail in $[5,6]$. 
Distributed strain measurement using stimulated Brillouin scattering in silica optical fibers is quite well established, however, its limits when strong deformation of the structure led to strain of more than $1 \%$.

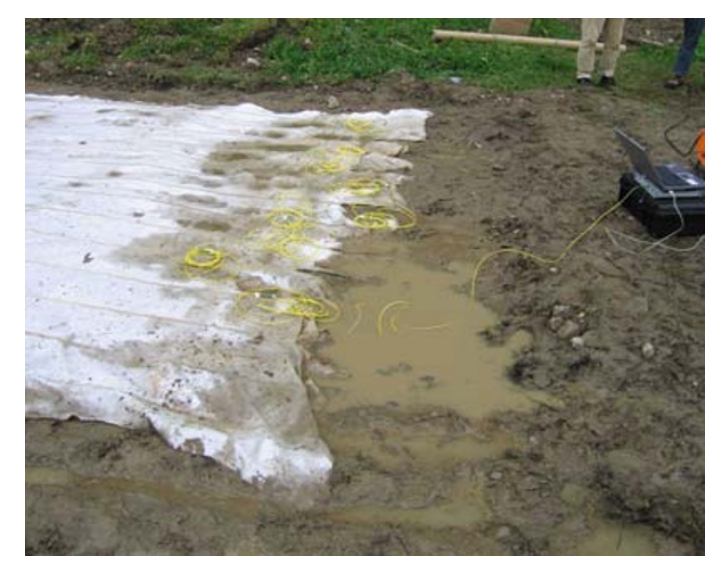

Fig. 13 Sensor-based geotextile mat being installed during construction of a gravity dam in Solina/Poland (textile: Saxon Textile Research Institute (STFI) e.V. Chemnitz).

\subsection{Distributed polymer fiber-optic sensor for monitoring of very large deformation in geo-structures}

Slopes, railway embankments or soil areas which show endangering stability behaviour like slipping, creeping or depression have usually less extended dimensions than dikes, and deformation to be detected can, however, require monitoring systems with the capability of measuring strain $(>1 \%)$. In such cases, polymeric optical fiber (POF) has some advantages. They are able to measure strain of up to $40 \%$ and more without significant distortion of light guiding properties; they are robust, allow easier handling, and have an acceptable price. Currently, the usable length of POF sensor fiber is about $100 \mathrm{~m}$ or slightly more.

In order to get smart geotextiles for application in areas with limited extensions, polymeric optical fibers have been integrated into nonwoven geotextiles using a warp-knitting technique [7]. The knitted fabrics can either be used as drainage or as narrow tape which poses a carrier for the sensor fiber. Figure 14 shows two samples of smart geotextiles. One important point during integration concerns the transfer of geo-structure's deformation to be monitored into the polymer optical sensor fiber. A method to integrate polymeric fiber-optic sensors without loosing their sensitivity was developed.

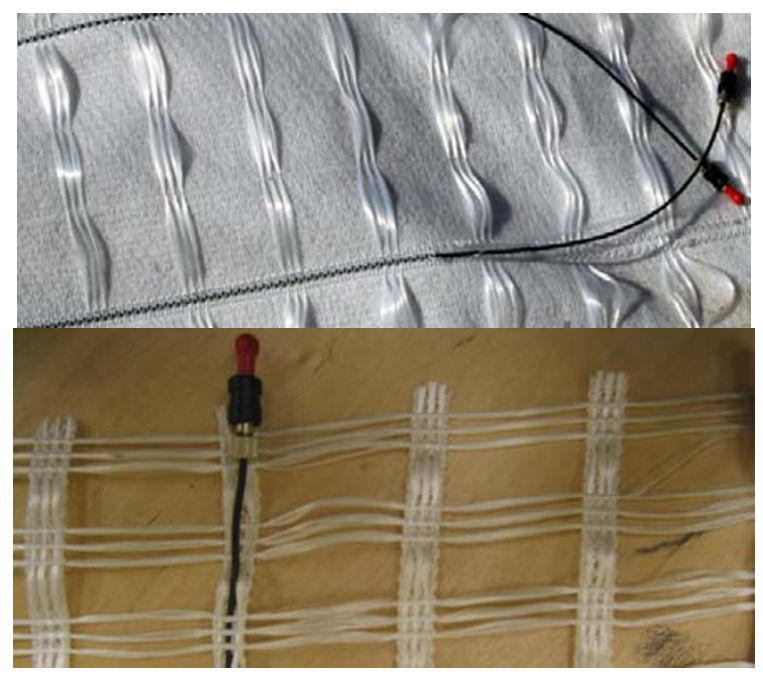

Fig. 14 Geotextiles with integrated polymeric fiber-optic sensors (photo and textile: STFI e. V. Chemnitz).

Deformation of the geotextile can be evaluated by measuring the POF elongation using the optical time-domain reflectometry analysis. This technique is well known and mainly used to locate errors in fiber-optic communication cables. However, it is also used as sensing method such as monitoring the bonding behaviour of heavy rock anchors in a gravity dam in Germany (referring to [4]). In principle, the time interval from launching the pulse into the fiber until the return of the backscattered light (pulse response time) is measured. It depends linearly on the distance of the scattering location initiated by a local or integral deformation. By using OTDR technique, it is known that the level of the backscattered light increases at locations where strain is applied to a polymer optical fiber. This effect is exploited for this sensing technology whereas some special questions concerning backscattering behaviour due to mechanical influences are being investigated. Basically, it must be possible to differentiate backscattered light caused by strain from such light and undesired 
effects such as bending and plastic deformation. For this purpose, a special test facility has been developed and used to introduce strain into the fiber. This test facility allows applying almost any desired strain distribution along the fiber by spooling it onto a coil under defined stress.

Figure 15 shows the increase of scattered light for applied strain up to $16 \%$. The relatively weak nonlinearity in this strain range becomes stronger for strain values up to $40 \%$. Above $40 \%$, the polyethylene coating was partially broken which led to significant attenuation. Test results also revealed that the level of scattered light due to constant strain decreased with time. It is being investigated whether this decrease converges to a stable value. Some other experimental results and an outlook concerning perfluorinated POF for sensor length of more than $100 \mathrm{~m}$ are described in [8].

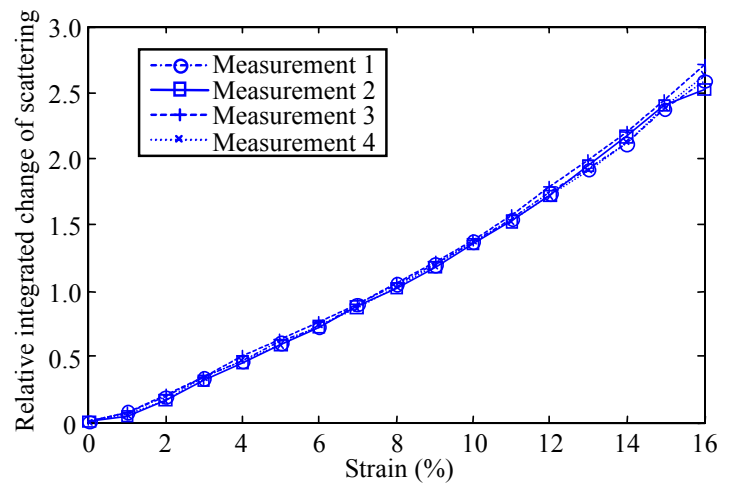

Fig. 15 Strain measurements (4 test series) at different locations along the POF [9].

A very important step in the research programme with POF is the improvement of spatial resolution. Some recent results are presented by Lenke et al. in [10]. The standard POF-OTDR sensor has been investigated and some new characteristics have been found. It can be shown that the increase of scattering due to the applied strain actually results from the perturbations of optical index in the fiber core that are smaller than $350 \mathrm{~nm}$ in dimension. The decreasing effect of the scattering level has been investigated. The suitability of using graded index polymeric optical fibers for strain measurement of slowly varying strain is shown and a new procedure to reverse the spatial blur that results from pulse broadening due to modal dispersion is proposed.

POF sensors have also been integrated in geotextile which were prepared for construction sites in Poland and Germany (Fig. 13). It could be demonstrated that the sensor structure itself as well as the integration procedure into geotextile tape was appropriate for use on-site. The sensing fibers endured the construction work of the dam.

In order to investigate and understand the force transfer mechanisms from the geotextiles to the fiber, strain tests with optical fibers integrated in textiles in the laboratory of the research partner STFI have been carried out. Among others, a so-called geogrid sample equipped with several integrated POF was clamped on two ends, and then a lateral displacement was forced with a hydraulic cylinder (Fig. 16) [6]. The measured results showed a successful integration into the textile and good strain transfer from the textile to the sensor fibers. For strain values exceeding $4 \%$, loss due to micro bend in the fiber arising from defects in the textile was observed. These defects can be avoided in future by improving textile integration process.

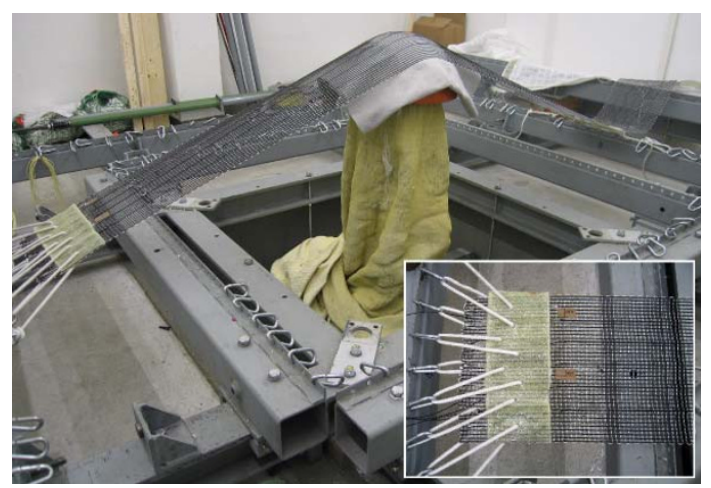

Fig. 16 Laboratory test in STFI e.V. in Chemnitz/Germany: forced deformation of a sensor-equipped geogrid and corresponding differential OTDR signal for different strain values.

In order to prove the sensor function under field conditions and reveal possible negative long-term effects in the soil, several sensor-equipped textiles 
were installed in a railway embankment near Chemnitz/Germany (Fig. 17). All sensors survived the installation process involving heavy machinery without any damage. Their long-term behaviour is being tested. A measurable strain in the fibers due to non-uniform settling is not expected because of heavy pre-compaction of the foundation.

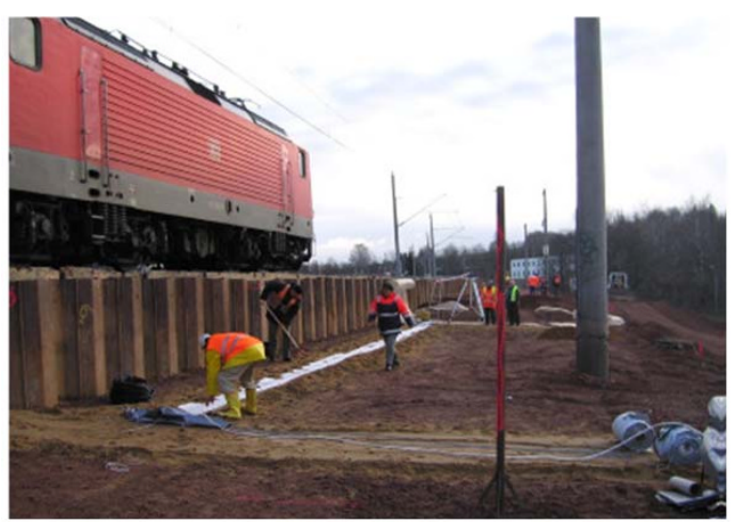

Fig. 17 Installation of sensor-equipped geotextiles in a railway embankment in Saxony/Germany [11].

\subsection{Polymeric fiber-optic sensors for assessment of masonry structures damaged by natural disasters}

Technical textiles are also used for retrofitting of masonry structures. This objective arises especially from the need of earthquake protection of historic buildings. In order to combine the stabilizing function of textiles with the signalization of severe deformation, a fiber-optic sensor system for embedment is being developed. This smart textile enables structural health online monitoring of retrofitted masonry structures. The motivation is not only to strengthen the masonry body and enhance its ductility by applying a textile, but also to monitor and detect the condition of the structures damaged or endangered by e. g. earthquakes. Typical faults that will be detected and monitored in this application are vertical cracks. In this case, POF sensors with their very high breakdown strain and ability to resolve the location of a crack are very promising. It has been found out that POF sensors not only enable distributed strain and strain profile measurement, but also are appropriate to detect very short strained sections in the scale of a few millimeters with a spatial resolution of up to $10 \mathrm{~cm}$. First laboratory test showed that it was possible to detect length changes of $1 \mathrm{~mm}$ at small gauge lengths [9]. This capability proves to be promising for the application of POF sensors in architectural textiles for crack detection in masonry structures.

Small-scale samples equipped with various technical textiles with integrated POF sensors were fabricated in cooperation with the textile partner STFI Chemnitz/Germany and tested in laboratory of the Institute of Reinforced Concrete Structures and Building Materials (IfMB) at the University of Karlsruhe/Germany. By using a resin matrix and common mortar, the sensor textiles were applied to one side of two-stone test samples. Figure 18 shows the test facility and the sample; details of the tests and related results are described in [9].

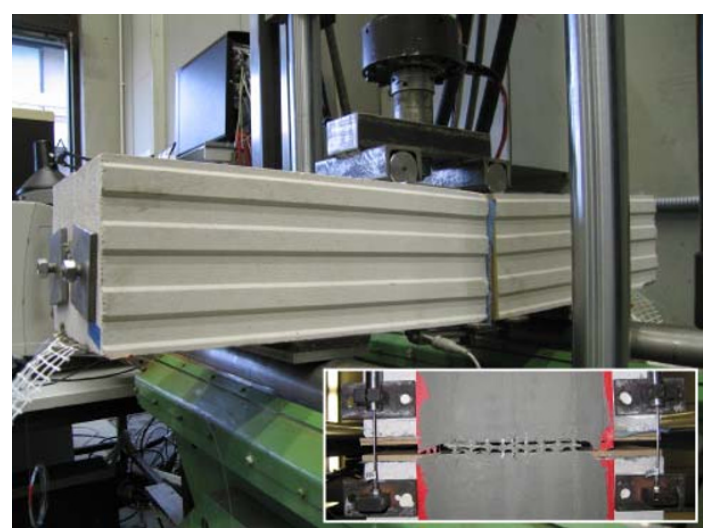

Fig. 18 Test setup with two-stone sample with sensor-textile on the bottom side (inclusion).

\section{4. pH sensor for early detection of potential danger of corrosion in concrete structures}

Steel-reinforced concrete structures such as sewer pipes, cooling towers or rock anchors are often exposed to a wide variety of damaging influences. Aside from mechanical stress, corrosion of steel is one of the most relevant damaging processes in steel-reinforced concrete. It presents a safety risk to people and environment because 
failure can occur without prior indication. Besides moisture and chloride ions concentration, $\mathrm{pH}$ value is a chemical parameter of major importance for health monitoring of steel-reinforced and pre-stressed concrete structures. The lifetime of steel-reinforced concrete structures depends strongly on their $\mathrm{pH}$ state as embedded steels in concrete structures are only passive at $\mathrm{pH}$ values higher than 9. For this reason, long-term monitoring of $\mathrm{pH}$ values in the range of 9 to 13 with a resolution of about $0.5 \mathrm{pH}$ units is relevant for early detection of potential corrosion condition.

Commercially available structure-integrated sensors for early detection of steel corrosion in concrete structures do not always sufficiently match the in-situ requirements. Fiber-optic based sensors are a promising technology for corrosion monitoring because they offer a large number of attractive features such as small size, flexibility, geometric versatility, resistance in corrosive and hazardous environments, no signal interference due to present moisture, in-situ and non-destructive measurement, and immunity against lightning strokes. In order to draw benefit from these advantages, a concrete-embeddable long-term stable fiber-optic $\mathrm{pH}$ sensor has been developed. The most challenging requirements concern its long-term stability under strong alkaline conditions within the $\mathrm{pH}$ range between 13 and 9 over a period of at least 25 years. The sensor has to be integrated in harsh environments and inaccessible places. It must be guaranteed that the sensing element has an intimate contact with the concrete matrix to pick up $\mathrm{pH}$ change. And finally, the price of $\mathrm{pH}$ sensors has to be as low as possible to enable the fabrication of multiple-sensor structures.

New fiber-optic $\mathrm{pH}$ sensor consists of a $\mathrm{pH}$-sensitive layer made of a $\mathrm{pH}$ indicator immobilized in a solid substrate which changes the colour depending on $\mathrm{pH}$ values. As a result of intense investigations, the absorption method is preferred because only this method provides reliable measurement results. In order to overcome instability problems resulting from decrease of the indicator concentration due to photodegradation or leaching out, drifts of the light source intensity or bending of optical fibers, a ratiometric method based on the use of ratio between the intensities at two different wavelengths (e.g. at the intensity maximum points or at the isosbestic point) is applied. Such a ratio of intensities is not altered by external factors. The measurement principle and some more details are described in [12]. Figure 19 shows the design of the sensor head.

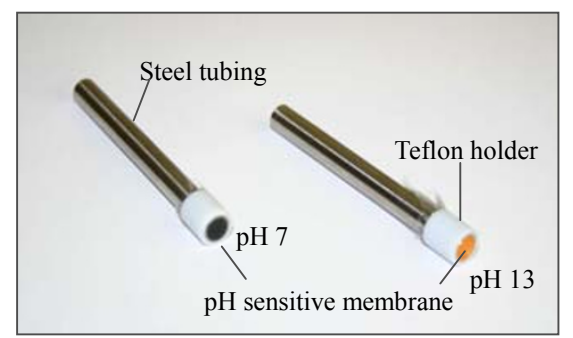

Fig. $19 \mathrm{pH}$ sensor head design (the head is pluggable and can be replaced, and the colour of the sensitive membrane varies depending on $\mathrm{pH}$ values).

The diameter of the head is $8 \mathrm{~mm}$; the sensitive layer is protected but sufficiently sensitive for the contact with the concrete matrix. The sensitive membrane must not exceed a definite thickness because the ion diffusion is hindered. In order to ensure a reliably stable thickness of the sensitive membrane, a special powder compacting tool for manufacture of $\mathrm{pH}$-sensitive membranes is developed.

The measurement resolution of the sensor for $\mathrm{pH}$ values between 9 and 12 is in the range of 0.1 to $0.6 \mathrm{pH}$ units depending on the $\mathrm{pH}$ values. The highest resolution can be achieved in the middle of the measurement range (between 9.7 and 11). One particular condition by now is that the $\mathrm{pH}$ sensitive membrane must not dry out. This requirement is mostly fulfilled in hydraulic engineering and geotechnique. In order to prevent drying out before integration into concrete structures, the $\mathrm{pH}$ sensitive membrane is protected by a small watertight topcoat (Fig. 20). 


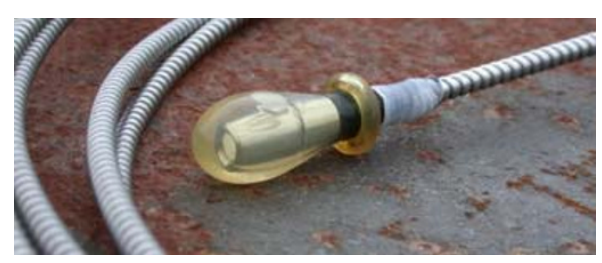

Fig. 20 Water-filled topcoat to prevent dehydration of the $\mathrm{pH}$ sensitive membrane (photo: STUMP GmbH).

Suitability of this sensor was successfully tested in steel anchors installed in the harbour of Rostock (North Germany) in summer 2010. Figure 21 shows two of totally $10 \mathrm{pH}$ sensor prototypes that were fixed on prefabricated anchor bodies (two in each anchor) before introducing them into the borehole. The topcoat (Fig. 20) was removed shortly before introducing the anchor into the borehole and grouting. This procedure ensured that the membrane maintained its hydrophilic properties. The sensors provided useful information about the $\mathrm{pH}$ values of the grout.

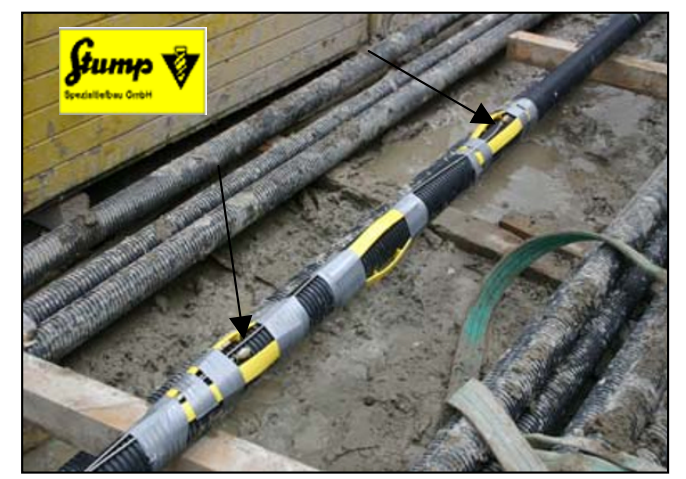

Fig. 21 Prefabricated anchors with fixed $\mathrm{pH}$ sensors (arrows).

The long-term function of the concrete embeddable $\mathrm{pH}$ sensor could be proved by a series of investigations carried out over the last 6 years. It could be observed that the most serious attacks concerning stability of $\mathrm{pH}$-sensitive membrane occurred in the first few months. The sensor concept has been optimized for commercial use and is being installed in cooling towers of a power plant.

\section{Conclusions}

This paper describes different types of fiber-optic sensors used for non-daily monitoring tasks in civil and geo-engineering. Fiber Bragg grating sensor arrays are used to monitor anchor deformation in difficult soil areas; fiber Fabry-Perot interferometer sensors are used as $\mathrm{AE}$ sensors embedded in large concrete piles to characterize its integrity and bearing capacity. Tiny concrete-embeddable $\mathrm{pH}$ sensors can be installed in steel-reinforced concrete structures to monitor the corrosion-free operation.

By using Brillouin frequency-domain analysis and OTDR technique for fiber-optic sensors, there are new possibilities for distributed fiber sensors especially when they are integrated in technical textiles. Strain measurements in geosynthetics and technical textiles enable monitoring of dikes, dams, and unstable or endangered slopes. By using polymer optical fibers with the capability of strain in the range of $1 \%$ to $40 \%$, monitoring of slopes, railway embankments or soil areas with less extended dimensions which show endangering stability behaviour is possible. Finally, measurement of crack opening in concrete or masonry structures helps to assess structures damaged by natural disasters.

Fiber sensor usage on-site requires special expertise and experience especially when long-term measurements have to be done. Measurement systems have to work stably under very different environmental conditions, such as temperature variations, moisture influences, chemical attacks to components of the sensor system, chemical interactions between the sensing elements or specific sensor materials and the measurand or environment. Packaging and ingress/egress areas for fiber-optic sensors must be very robust. However, the most relevant issue for long-term monitoring sensor systems concerns the application of the sensing element and/or sensor fiber itself. Application, gluing, crimping or fixing must resist cycling thermal and mechanical loads. In order to consider all quality-related aspects, the only way is to aim at validated sensor systems and validated 
application methods. By using this methodology, users get the confirmation that the sensor or the measurement system works as reliably as demanded.

Open Access This article is distributed under the terms of the Creative Commons Attribution License which permits any use, distribution, and reproduction in any medium, provided the original author(s) and source are credited.

\section{References}

[1] M. Schallert, J. Stahlmann, and W. R. Habel, "Strukturintegrierter faseroptischer Mikrodehnungsaufnehmer für die Bewertung von Betonpfählen mit dynamischen Pfahlprüfmethoden," (Structureintegrated fiber-optic microstrain sensor for evalutation of concrete piles by means of dynamic pile testing methods), in Messen in der Geotechnik 2010, Scientific series published by Technical University of Braunschweig, Inst. for Foundation Engineering and Soil Mechanics, Braunschweig, pp. 265-286, 2010.

[2] M. Schallert, W. R. Habel, I. Göbel, J. Stahlmann, and P. Wardinghus, "Dynamic, and static testing of concrete foundation piles with structure-integrated fiber optic sensors," in Proc. of the 8th International Conference on Application of stress wave theory to piles, Lisbon, Portugal, September, pp. 625-635, 2008.

[3] M. Schallert, W. R. Habel, and D. Hofmann, Strukturanalyse von Betonpfählen durch eingebettete faseroptische Sensoren (Analysis of Concrete Foundation Piles Using Structure-Integrated Fiber-Optic Sensors in tm-Technisches Messen, vol. 75. München: Oldenbourg-Verlag, 2008, pp. 485-500.

[4] W. R. Habel and T. Gutmann, "Embedded Quasi-distributed Fiber Optic Sensors for Long-term Monitoring of 4,500 kN Rock Anchors in the Eder Gravity Dam in Germany," in Proc. of SHMII-2
Conference, Shenzhen, China, BALKEMA Taylor \& Francis, vol. 1, pp. 289-297, 2006.

[5] N. Nöther, A. Wosniok, K. Krebber, and E. Thiele, “A Distributed fiber optic sensor system for dike monitoring using Brillouin optical frequency domain analysis," in Proc. Conf. on Smart Structures and Materials, SPIE, San Diego, USA, 2008, vol. 6933 , pp. 69330T-1-69330T-9.

[6] A. Wosniok, N. Nöther, K. Krebber, and E. Thiele, "Distributed monitoring of mechanical deformation in river dikes," in Proc. of the Conf. Eurosensors XXII Dresden, Düsseldorf: VDI-Verlag, 2008, pp. 1457-1460.

[7] P. Lenke, S. Liehr, K. Krebber, F. Weigand, and E. Thiele, "Distributed strain measurement with polymer optical fiber integrated in technical textiles using the optical time domain reflectometry technique," In Proc. of the 16th International POF Conference, Turin, Italy, Sept., pp. 21-24, 2007.

[8] S. Liehr, M. Wendt, and K. Krebber, "Distributed strain measurement in perfluorinated polymer optical fibers using optical frequency domain reflectometry," Meas. Sci. Technol., vol. 21, no. 9, pp. 094023-1-094023-6, 2010.

[9] S. Liehr, P. Lenke, M. Wendt, K. Krebber, M. Seeger, E. Thiele, H. Metschies, B. Gebreselassie, and J. C. Muenich, "Polymer Optical Fiber Sensor for Distributed Strain Measurement and Application in Structural Health Monitoring," IEEE Sensors J., vol. 9, no. 11, pp.1330-1338, 2009.

[10] P. Lenke, S. Liehr, and K. Krebber, "Improvements of the distributed strain sensor based on optical time domain reflectometry measurement in polymer optical fibers," presented at Proc. 17th Intern. Conf. on Plastic Optical Fibers, Santa Clara, USA, 2008.

[11] K. Krebber, P. Lenke, S. Liehr, et al., "Technology and Application of Smart Technical Textiles Based on POF," presented at Proc. 17th Intern. Conf. on Plastic Optical Fibers, Santa Clara, USA, 2008.

[12] N. Dantan and W. R. Habel, "Monitoring of corrosion protection - a concrete-embeddable $\mathrm{pH}$ optode," in BFT International-Concrete Plant + Precast Technology (Betonwerk+Fertigteiltechnik) Bau Verlag - Springer Science + Business Media, vol. 72, pp. 48-55, 2006. 